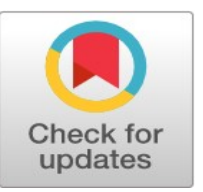

PRIMARY RESEARCH

\title{
A study on formation of saltwater-freshwater interface and upconing in coastal aquifers based on experiments with hydraulic models
}

\author{
Byoung Ryoun Koh ${ }^{1}$, Young Hun Oh ${ }^{2}$, Dong Il Park ${ }^{3}$ * \\ 1, 2, 3 School of Civil Engineering, Jeju International University, Korea
}

\author{
Index Terms \\ Hydraulic Model \\ Coastal Aquifer \\ Interface \\ Intrusion \\ Upconing
}

Received: 11 June 2016

Accepted: 12 July 2016

Published: 27 October 2016

\begin{abstract}
This study was to evaluate saltwater interface and upconing caused by the intrusion of saltwater into coastal aquifers. There are many coastal areas in the around the world where the issue of seawater intrusionis troublesome. This was an experimental study using a hydraulic model to observe characteristics of the interface between freshwater and saltwater caused by the difference in density, as well as to research the formation of upconing, a seawater wedge occurred when drain in a well. Results of the experiment showed that the boundary between saltwater and freshwater in a coastal aquifer isproportional to the hydraulic gradient in dynamic state and inversely proportional to the density of fluid, so it is formed at a position lower than the sea level. It was confirmed that the upconing caused by excessive pumping was related to the depth to the saltwater-freshwater boundaryin the bottom of a pumping well. It was also confirmed that the time duration required for the saltwater-freshwater boundary to restore its original state was more than twice the duration of upconing. By using the hydraulic model, it was possible to observe the formation of saltwater-freshwater boundary and upconing phenomenon in coastal aquifers distributed around islands or coastal areas. The purpose of this study was to obtain basic information such as the position of wells and pumping capacity to obtain groundwater more securely, which is not contaminated owing to seawater intrusion which may occur when pumping in coastal aquifer.
\end{abstract}

(c) 2017 The Author(s). Published by TAF Publishing.

\section{INTRODUCTION}

The saltwater-freshwater relationship in aquifers of islands and coastal areas has become a significant factor in terms of water. In particular, to secure freshwater in aquifers located in coastal areas, it is required to understand the characteristics of the saltwater-freshwater interface in an aquifer in relation to the freshwater outflow in the aquifer. The initial characterization analysis of a coastal saltwater desalination interface was independently performed by two European scientists: [1], [2]. Their analyses were aimed to interpret the boundary interface assuming a hydrostatic condition in a uniform coastal aquifer; how- ever, it is true the groundwater flow in the actual coastal area is formed by the seawater wedge as a salt-freshwater interface by dynamic leakage as shown in Fig.1 [3].

This study was aimed to provide the information such as on the location of the well and the allowed pumping amount with regard to seawater intrusion in the island or coastal area by observing the formation of the seawater wedge as a saltwater-freshwater interface considering the characteristic of forming the interface between freshwater and saltwater and carrying out an experimental study on the formation of upconing according to the seawater wedge with regard to seawater intrusion in islands or coastal areas.

\footnotetext{
* Corresponding author: Dong Il Park
}

†Email: joy830210@naver.com 


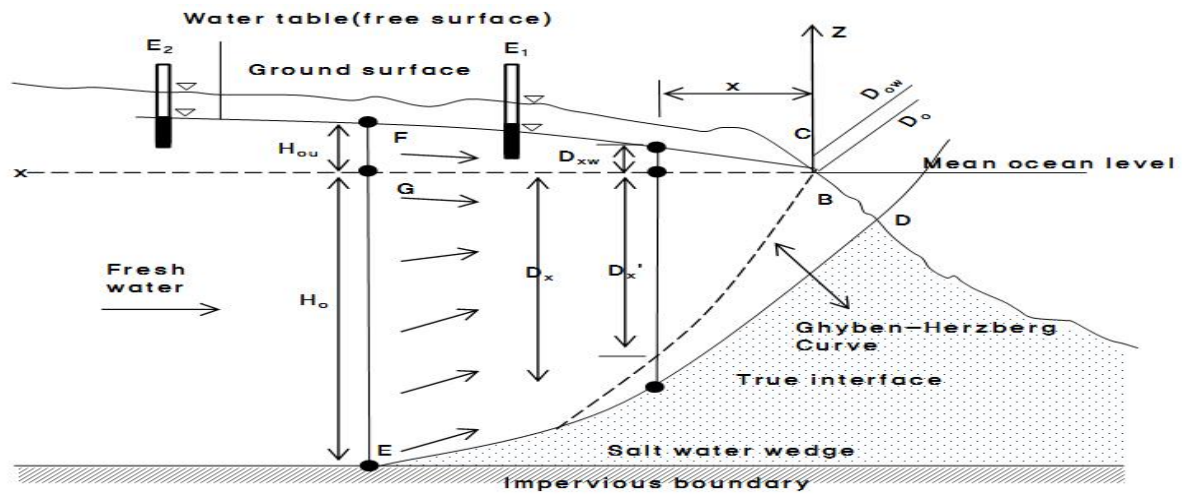

Fig. 1. Diagrammatic sketch indicating the Ghyben-Herzberg curve as compared with the true interface in an unconfined aquifer

\section{DESIGN OF LAB-SCALE HYDRAULIC MODEL}

In order to carry out the experiment by taking into account the seawater intrusion in coastal areas and islands, the design of a hydraulic model consisted fora porous layer as shown in Fig.2 to reflect the characteristics of coastal aquifers. Among the characteristics reflected in the design, the location of interface between freshwater-saltwaterwas selected to monitor the seawater intrusion and upconing while pumping in the hydraulic model and also to observe the restoration of the disturbed interface through natural flow of groundwater [4].

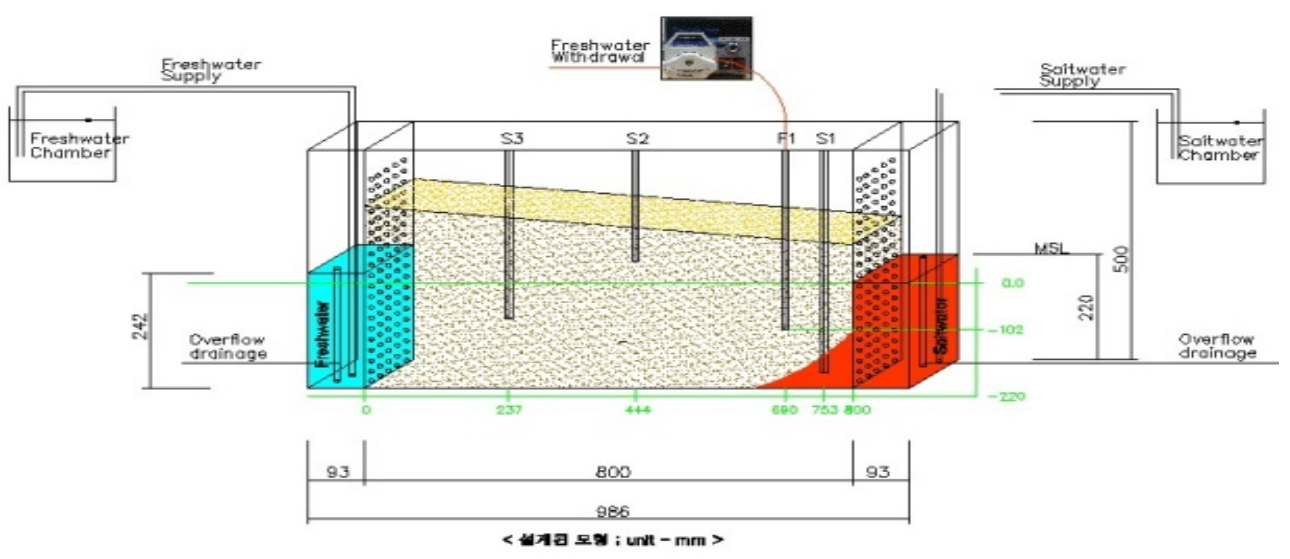

Fig. 2 . Design of hydraulic model and conditions for experiment

TABLE 1

CONDITIONS FOR EXPERIMENT

\begin{tabular}{lll}
\hline \hline Assortment & & Sand aquifer \\
\hline Freshwater & Water level & $242 \mathrm{~mm}$ \\
& Density & $1.000 \mathrm{~g} / \mathrm{m} \ell$ \\
Saltwater & Water level & $218 \mathrm{~mm}$ \\
& Density & $1.04 \mathrm{~g} / \mathrm{m} \ell$ \\
& Size of water tank $(\mathrm{mm})$ & $\mathrm{L} 986 \times \mathrm{B} 100 \times \mathrm{H} 500$ \\
& Aquifer size $(\mathrm{mm})$ & $800 \times 100 \times 480 \sim 310$ \\
\hline \hline
\end{tabular}




\section{STUDY OF INTERFACE AND UPCONING BY USING THE MODEL}

\section{A. Experiment of Saltwater-Freshwater Interface}

For the equilibrium state of a coastal aquifer in the static hydraulic condition, it was interpreted based on the Ghyben-Herzberg principle( $\mathrm{h}=40 \mathrm{hf})$ that a freshwater layer is floating over seawater, and the thickness of the layer reaches over 40 times the average freshwater layer. However, as there is no clear-cut boundary of saltwaterfreshwater and the boundary layer tends to be a fairly thick transition zone showing gradual change in salinity [5]. Therefore, to figure out the formation of a seawater wedge on the saltwater-freshwater boundary, an experiment was conducted with factors shown in Table 1.

As shown in Fig.3 results of the experiment with a hydraulic gradient of $2.75 \%$ showed a $98.8 \mathrm{~mm}$ fall from the sea level in a seawater wedge on the saltwater-freshwater boundary. These results showed a sharp straight line at static sea level; however, if there is any external influence such as a hydraulic grade, then the flow turns into a dynamic state and the seawater wedge forms a gentle parabolic shape under the sea surface [6].

The results confirmed the Ghyben-Herzberg principle suggested by [7], [8]. This result is due to the influence of groundwater flow in the aquifer.

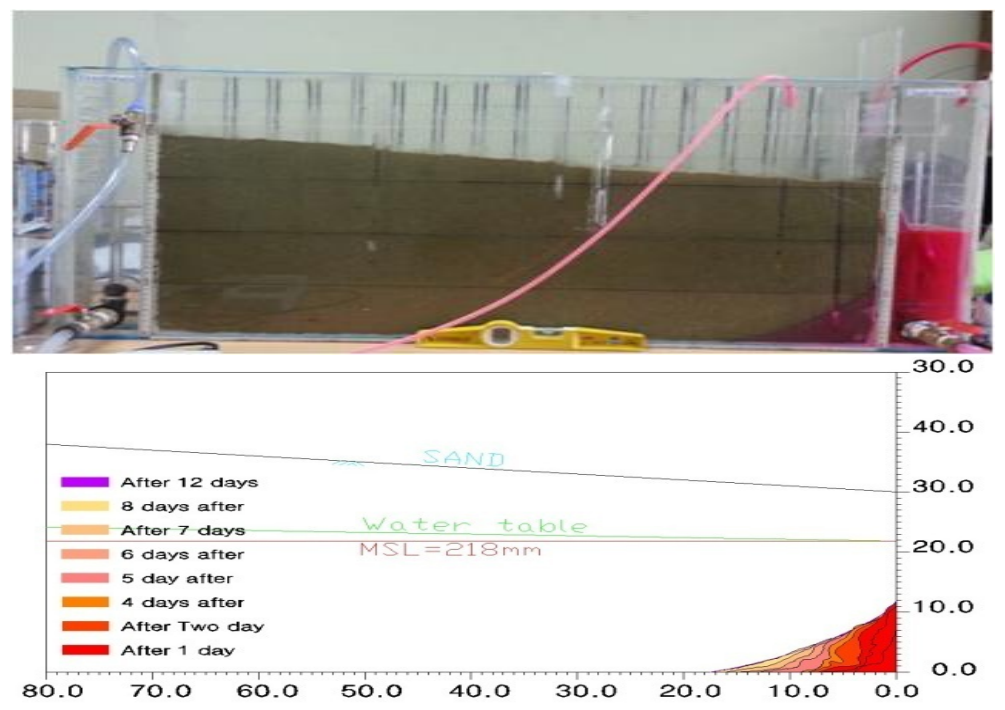

Fig. 3 . ( $a$ and b) Result of the experimenton seawater interface(wedge) behavior

\section{B. Experiment of Upconing}

When an aquifer contains an underlying layer of saltwater and is pumped by a well penetrating only the upper freshwater portion of the aquifer, a local rise of the interface below the well occurs. This is called upcoming phe- nomenon. When pumping becomes excessively in a well installed in a coastal aquifer,the upconing occurs as shown in Fig. 4 with the rise of sea water and the groundwater becomes polluted owing to excessive salinity caused by seawater intrusion as the sea water reaches the well.

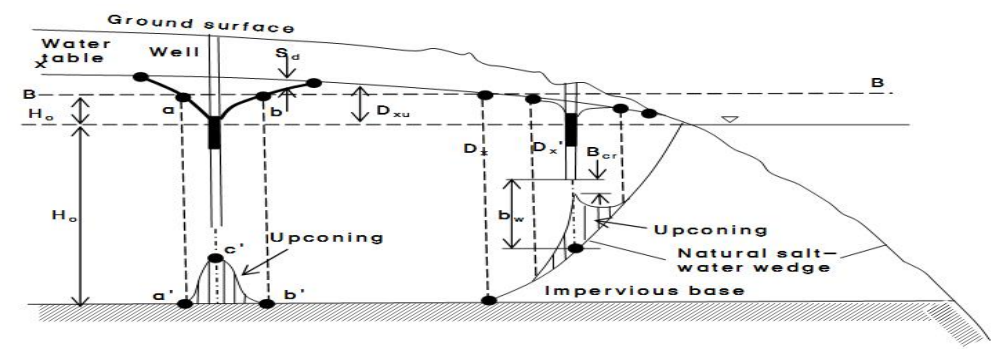

Fig. 4 . Upconing of saltwater beneath wells [9] 
The height of the salt water rise caused by upcoming in Fig.4 can be interpreted as shown in Fig.5. The experiment's results showed that upcoming caused by overpumping occurred as shown in Fig.6.

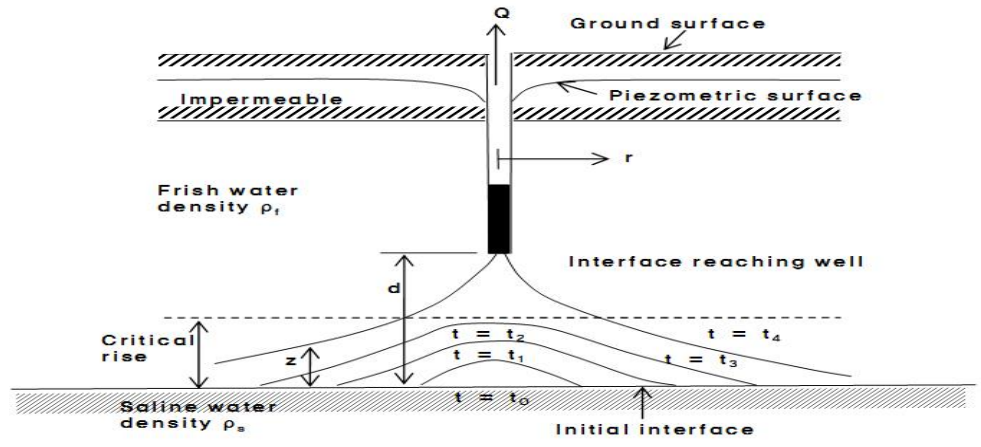

Fig. 5 . Upcoming of underlying saltwater to a pumping well [10]

To obtain the height of the saltwater rise, $z$, based on the results by using the Dupuit's assumption and the Ghyben-Herzberg relations, the pumping capacity was calculated for the following two cases: when not affected by upconing and when affected by upconing. In the following equations, $\mathrm{Q}$ is the pumping capacity, $\mathrm{d}$ is the depth to the boundaries between freshwater and saltwater before pumping water from the well bottom, $\mathrm{K}$ is the permeability, and $\Delta \rho$ is the density difference between freshwater and saltwater:

1) Pumping capacity not affected by upconing (For $\mathrm{B}, \mathrm{d} / 2=47.5 \mathrm{~mm})$ $Z=\frac{Q}{2 \pi d k\left(\frac{\Delta p}{\rho f}\right)}$

$$
\begin{aligned}
& =\frac{0.05}{2 \times \pi \times 4.75 \times 0.0181 \times\left(\frac{0.04}{1.000}\right)} \\
& z=\frac{Q}{2 \pi d k\left(\frac{\Delta p}{\rho f}\right)}=\frac{0.088}{2 \times \pi \times 9.5 \times 0.0181 \times\left(\frac{0.04}{1.000}\right)} \\
& =2.314 \mathrm{~cm} \\
& Q_{\max } \leq \pi d^{2} K\left(\frac{\Delta p}{p f}\right) \leq \pi \times 4.752^{2} \times 0.0181 \times\left(\frac{0.04}{1.000}\right)= \\
& 0.051\left(\frac{\mathrm{cm}^{3}}{\mathrm{sec}}\right) \\
& \text { 2) Pumping capacityaffected by upconing (for } \mathrm{A}, \mathrm{d}=95 \mathrm{~mm}) \\
& Z=\frac{Q}{2 \pi d k\left(\frac{\Delta p}{\rho f}\right)}=\left(\frac{0.088}{2 \times \pi \times 9.5 \times 0.0181 \times \frac{0.04}{1.000}}\right) \\
& =20.36 \mathrm{~mm} \\
& \frac{z}{d}=0.214 \\
& Q_{\max } \leq \pi d^{2} K\left(\frac{\Delta p}{p f}\right) \leq \pi \times 9.5^{2} \times 0.0181 \times\left(\frac{0.04}{1.000}\right)= \\
& 0.051\left(\frac{\mathrm{cm}}{\mathrm{sec}}\right)
\end{aligned}
$$

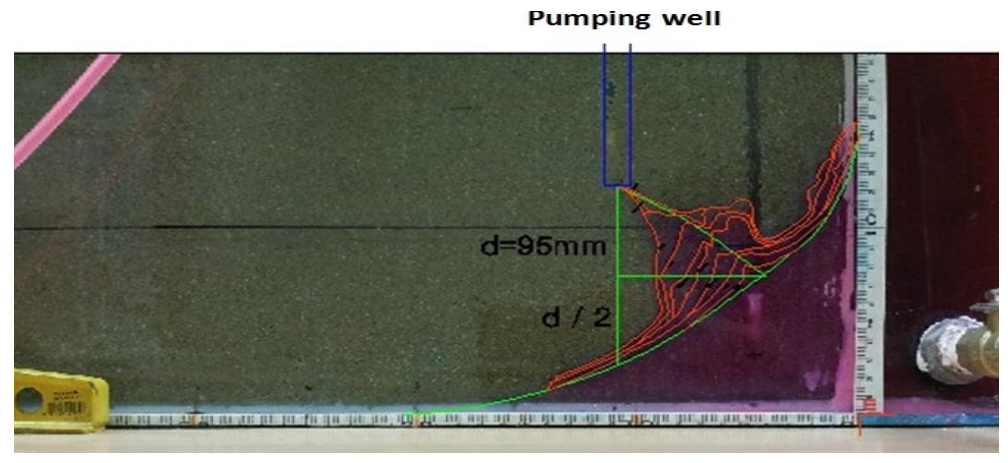

Fig. 6 . Around $50 \%$ of the respondent are using

\section{DISCUSSION}

Results of the experiments are presented in Table 1. For $B(d=47.5 \mathrm{~mm})$ in Table2, upconing did not happen. For $A(d=95 \mathrm{~mm}), z / d=0.214$ and $\mathrm{z} / \mathrm{d}=$ less than 0.5 , so the well height is appropriate, but it was found that upconing occurred when pumping, which reach the lower part of the well after 17 hours.

In the experiment, upconing did not occur on the saltwater-freshwater interface located in the bottom of the 
well while pumping water, but owing to the flow of fresh water in the aquifer, it occurred at a point at which a horizontal line extended from a point located at a half of the depth of the interface from the well bottom was met with the interface. When the upconing reached the well, it formed a symmetrical shape on the saltwater-freshwater boundary (Fig.6.).

Therefore, to obtain the maximum pumping capacity (Q) while not affected by upconing at the interface caused by seawater intrusion when pumping water in the well, it is required to dig a well, of which $\mathrm{d}$ would be $1 / 2$, to prevent the seawater intrusion.
When upconing occurs in a well, we stopped pumping for 17 hours and left the well as it is to remove the upconing by natural flow of groundwater in aquifer. The time duration required to recover the well was 30 hours, which was two times that of the upconing duration. In other words, after upconing is occurred, it is required twice the time duration of upconing to recover a well to its original state without seawater intrusion after stopping pumping. It suggests that if groundwater is contaminated owing to seawater intrusion via upconing, it will take enormous financial resources and time to recover it to the original state.

TABLE 2

\begin{tabular}{ccc} 
EXPERIMENT ACCORDING TO THE WELL BOTTOM AND THE INTERFACE DISTANCE \\
\hline \hline Item & $\begin{array}{c}\mathrm{A} \\
(\mathrm{d}=95 \mathrm{~mm})\end{array}$ & $\begin{array}{c}\mathrm{B} \\
(\mathrm{d} / 2=47.5 \mathrm{~mm})\end{array}$ \\
\hline Total pumpage $(\mathrm{m} \ell)$ & 5362.20 & 2167.20 \\
Pumping time $(\mathrm{hr})$ & 17 & 12 \\
Pumping rate $(\mathrm{m} \ell / \mathrm{min})$ & 5.26 & 3.01 \\
Increased level of saltwater $(\mathrm{mm})$ & 20.36 & 23.14 \\
Well bottom-interface $(\mathrm{mm})$ & 95.00 & 47.50 \\
z/d & 0.214 & 0.487 \\
Maximum permissible pumpage (m $\ell / \mathrm{min})$ & 12.30 & 3.06 \\
Upconing (seawater intrusion) time (hr) & 17 & - \\
Recovery time of upconing (hr) & 30 & - \\
Result & Upconing & None \\
\hline \hline
\end{tabular}

\section{CONCLUSION}

This study was conducted on a upconing which is the saltwater-freshwater interface using a lab-scale hydraulic model. The research results were as follows: 1. Concerning the development of a sea water wedge which is the saltwater-freshwater interface occurred by the intrusion of seawater, it was found that the groundwater level has a close relationship with not only the difference in density, but also the gradient of underground water table, and the location of the interface would be decided depending on the gradient of groundwater table and flow rate of ground water in the aquifer. Therefore, it was found that the saltwaterfreshwater interface of a coastal aquifer is proportional to its hydraulic gradient in a dynamic state and inversely proportional to the density of fluid, so the interface is formed in a place lower than the sea level.

2 . When pumping water in a well located in a coastal aquifer, it was confirmed that upconing started at the inter- section of the saltwater-freshwater boundary with a horizontal line extended to the coast at a point located at the one-half depth to the salt-freshwater boundary in the well bottom. To get maximum pumping amount (Q) from a well without the influence of upconing, it is recommended to install a well at the depth of one-half (i.e., the depth from the well bottom to the interface) to get a good result. In addition, when upconing occurs, the time duration required to recover to its original state is twice times that of forming upconing. In other words, it is very difficult to recover to the original state, when the saltwater contamination occurs owing to upconing.

\section{ACKNOWLEDGMENTS}

This research was supported by a grant (Code:14AWMPB066761-02) from the AWMP Program funded by the Ministry of Land, Infrastructure and Transport of Korea. 


\section{REFERENCES}

[1] J. Drabbe and W. B. Ghijben, Nota In Verband Met De Voorgenomen Putboring Nabij Amsterdam. Hauge, Netherland: The Hague, 1888.

[2] A. Herzberg, "Die wasserversorgung einiger nordseebader," Journal Gasbeleucht Wasserversorg, vol. 44, pp. 815-819, 1901.

[3] N. S. Park, P. S. Huyakorn, Y. S. Wu and M. D. Barcelo, "A sharp-interface salt water intrusion code for layered aquifer systems," in Society of Civil Engineers International Symposium on Engineering Hydrology, 1993, pp. 1159-1164.

[4] C. S. Lowry and M. P. Anderson, "An assessment of aquifer storage recovery using ground water flow models," Ground Water, vol. 44, no. 5, pp. 661, 2006. DOI: 10.1111/j.1745-6584.2006.00237.x

[5] N. S. Park, S. H. Hong and M. G. Sim, "Development of optimal pumping model for coastal region using genetic algorithms and parallel processing," in Korean Society of Civil Engineers Conference, vol. 2002, pp. 397-403.

[6] A. I. Kashef, "Management and control of salt-water-intrusion in coastal aquifers," Critcal Reviews in Environmental Science and Technoligy, vol 7, no 3, pp. 217-275, 1977. DOI: 10.1080/10643387709381652

[7] M. K. Hubbert, "The theory of ground-water motion," The Journal of Geology, vol. 48, no 8, pp. 785, 1940.

[8] R. E. Glover, "The pattern of fresh-water in a coastal aquifer," Journal of Geophysical Research, vol. 64, no.4, pp. 457459, 1959.

[9] A. S. Kashef, Groundwater Engineering. New York, NY: McGraw-Hill Inc, 1987, pp. 455.

[10] A. Schmorak and A. Mercado, "Upconing of freshwater-sea water interface below pumping wells," Water Resources Research, vol. 5, no. 6, pp. 1290-1311, 1969.

— This article does not have any appendix. - 